\title{
Body composition in Indian children and adolescents with type 1 diabetes
}

\author{
Vaman Khadilkar, Lavanya Parthasarathy, Anuradha Khadilkar, Shashi Chiplonkar \\ From 8th APPES Biennial Scientific Meeting \\ Darwin, Australia. 29 October - 1 November 2014
}

Studies suggest that children and adolescents with type 1 diabetes (T1DM) have suboptimal body composition with higher fat mass and lower bone mass. Aim of our study was to compare body composition of Indian children with type 1 diabetes with age gender matched healthy controls.

In a cross-sectional study, body composition parameters were measured by DXA (Lunar DPX PRO, Total Body Densitometer) in 160 (74 boys) children with T1DM (attending type 1 diabetes clinic) and age gender matched healthy controls. $\mathrm{Z}$ scores for bone mineral content (TBBMC) for age, bone area for age (TBBA), TBBMC for TBBA, TBBA for height, lean body mass (LBM) for height, TBBMC for LBM [1] and fat and lean mass [2] were computed using Indian reference data. Anthropometry and tanner staging (TS) was assessed for all children. The height (HAZ), weight (WAZ) and BMI (BAZ) were converted to $\mathrm{Z}$ scores using contemporary Indian references [3].

Mean ages of boys and girls were 11.4 $\pm 3.3 \mathrm{y}$ and 10.9 $\pm 3.4 \mathrm{y}$ respectively. For both genders HAZ (boys -0.5 vs 0.3 , girls -0.5 vs 0.1 ) and WAZ (boys -0.6 vs 0.0 and girls -0.5 vs -0.1 ) were significantly lower in diabetics, though BAZ scores were comparable. Similarly, mean Z scores were significantly lower for fat mass (boys -0.1 vs 0.2 , girls -0.1 vs 0.1 ) and higher for lean mass (boys -0.4 vs -1.1 , girls -0.3 vs -0.6 ) in diabetics for both genders. Diabetic boys and girls had lower android fat percent (boys 20 vs 25 , girls 28 vs $32, \mathrm{P}<0.05$ ) when compared with controls. Mean $\mathrm{Z}$ scores for bone parameters showed TBBA for age (boys -0.1 vs 0.5 , girls -0.1 vs 0.3 ), TBBMC for age (boys -0.1 vs 0.6 , girls -0.1 vs 0.3 ) and TBBMC for LBM (boys -0.4 vs 0.0 , girls -0.5 vs -0.2 ) were significantly lower in diabetics while all other bone parameters were comparable.

Hirabai Cowasji Jehangir Medical Research Institute, Jehangir Hospital, Pune, Maharashtra, India

Submit your next manuscript to BioMed Central and take full advantage of:

- Convenient online submission

- Thorough peer review

- No space constraints or color figure charges

- Immediate publication on acceptance

- Inclusion in PubMed, CAS, Scopus and Google Scholar

- Research which is freely available for redistribution 